\title{
Legislação de Pessoal: Três Momentos
}

CORSÍNDIO MONTEIRO DA SILVA

Assistente Jurídico do DASP

SUMÁRIO: 1 - Férias do servidor público federal. Incluem-se no capítulo dos direitos e vantagens do funcionário. São consideradas um direito-dever. Antecedentes legais. O que constitui ilícito. Impossibilidade de compensação de faltas. Interrupção das férias, quando se pode dar. Características das férias. Quando podem ser gozadas. Parcelamento. Inegociabilidade. Sugestão para casos especiais de impossibilidade de gozo do período de férias. Vantagens auferidas enquanto em exercício concedidas nas férias. Funcionários que operam com Raios $\mathrm{X}$ e substâncias radioativas: regime especial. Magistério. Servidores requisitados para órgãos da Justiça Eleitoral. II - Regime de trabalho do servidor público. Matéria de natureza precipuamente regulamentar. A jornada de trabalho tem estreita relação com as especificações de classe. Matéria que precisa ser revista com a implantação do novo plano de classificação de cargos. Grupos em que se inscrevem hipóteses examinadas. Regulamentação vigente. Casos específicos. III - A licença em caráter especial. Antecedentes legais. Fator preponderante para sua concessão. Motivos que ensejam a interrupção da contagem do período aquisitivo. Condicionamento na concessão. Cômputo do decênio. Aspectos emergentes. Conversão da licença em vantagem financeira: idéia que poderia ser examinada. Outra providência que merecia estudo por parte do legislador: computar em dobro o tempo para efeito de gratificação adicional por tempo de serviço. Caso de acumulação de cargos. Gozo parcelado da licença. Escala organizada pela chefia. O que se entende por "direitos $e$ vantagens" no caso da licença em caráter especial. Funcionário afastado para exercer mandato eletivo.

Incluem-se as férias no capitulo dos direitos e vantagens do funcionário. É evidente que férias não são somente direito e nem Só vantagem, pois que o gozo delas é também do interesse da Administração para a higiene mental do seu servidor.

São elas consideradas um direito-dever, tanto que o gozo delas é obrigatório, embora essa regra de obrigatoriedade seja endereçada ao administrador: se o funcionário deixar de gozar 
as férias por esta ou aquela circunstância tão-somente perderá o direito a desfrutá-las. Isto por que, não raro, o funcionário deixa de tirar as férias no próprio interesse do Serviço.

De início, as férias eram uma concessão do Estado a seu servidor, passando pelo primeiro Estatuto dos Funcionários Públicos Civis da União - Decreto-lei no 1.713, de 28 de outubro de 1939 - a ser obrigatórias (art. 145) já sob a égide da Carta de 1937.

Na Constituição anterior, a de 16 de julho de 1934, fora preconizada "férias anuais remuneradas" para a legislação trabalhista, mas os servidores públicos e os bancários já gozavam do favor antes mesmo da guerra de 1914, e o próprio trabalhador já desfrutava de férias em 1936, sendo que a Lei no 4.582 , de 24 de dezembro de 1925, deferia 15 dias de férias, remuneradas, anualmente, "aos empregados e operários de estabelecimentos comerciais, industriais e bancários e de instituições de caridade e beneficência", incluídos os empregados de empresas jornalísticas.

Aduz Contreiras de Carvalho o seguinte a respeito das férias: "Reconhecendo a necessidade, para o funcionário, de um repouso anual com aquele objetivo, tornou o Estado obrigatório o gozo das férias, não sendo lícito ao servidor público recusá-lo, sob qualquer pretexto". (Estatuto dos Funcionários Públicos Interpretado, 3a ed. 1964, I, 315).

Com efeito, lícito não é ao funcionário recusar o gozo das férias mas também não é ilícito deixar de desfrutar o direito a elas. llícito é o chefe impedir que o funcionário goze as férias porém não de o funcionário deixar de desfrutá-las. Há ocasiões em que o funcionário tem certos encargos como o de chefia ou assessoramento que moralmente o impedem de tirar férias de 30 dias. Não vamos citar o caso do Presidente da República nem dos Ministros de Estado, mas de certos altos funcionários que, pela natureza das suas responsabilidades, geralmente não se afastam do cargo. Há mesmo funcionários de categoria menor que dificilmente tiram férias sem que com isso estejam praticando um ilicito administrativo. Inclusive não ficam as férias ao arbítrio do chefe, salvo no que se refere à organização da escala. Fica a critério do chefe da repartição a fixação do período de férias dos funcionários que lhe estâo diretamente subordinados, levando em consideração o interesse e a conveniência do serviço.

Em geral, certa época do ano, os funcionários se manifestam sobre o período de sua preferência para gozar as férias, 
cumprindo ao chefe estabelecer a pauta para evitar o esvaziamento das repartições em algumas épocas, como por ocasião das festas natalinas ou de carnaval. Em determinadas repartições, a chefia pode, e deve, alterar a escala se tiver algum assunto de urgência a ser tratado e ser indispensável a assistência técnica de determinados funcionários.

Primitivamente, isto é, antes do advento do primeiro Estatuto - Decreto-lei n? 1.713 , de 28 de outubro de 1939 - as férias eram de 15 dias anuais, sendo que aquele diploma legal o ampliou para 20 dias consecutivos, e o atual - Lei n? 1.711, de 28 de outubro de 1952 - para 30 dias.

Cumpre notar que não pode haver compensação de faltas: qualquer falta ao trabalho não pode ser levada à conta de férias, como se o funcionário tivesse uma conta-corrente na repartição para elidir sua falta de assiduidade. Mesmo o funcionário que não goze férias porque não quer ou não pode, por esta ou aquela circunstância, não pode fixar como norma de vida funcional deixar de comparecer sistematicamente ao Serviço sob pretexto de que não gozou férias. É claro que um funcionário altamente responsável, cumpridor de seus deveres, que deixa de gozar as férias no interesse do Serviço, pode gozar de certo privilégio junto à chefia, tudo a depender das circunstâncias, sem que isso possa arvorar-se em regra de procedimento funcional.

Não pode haver compensações porque a falta ao trabalho constitui ilícito que implica detrimento do serviço que não pode Ser ilidido com o fato de o funcionário abrir mão de suas férias, ainda que em parte. Talvez seja por isso que o legislador estatutário de 1939 e de 1952 falaram em dias consecutivos, mesmo porque aquele período fixado na lei é o essencial para que o funcionário recomponha suas energias. Nem 31 nem mesmo 20 dias, período que já fora considerado o ideal.

Se se permitisse a compensação, não só as férias falhariam em sua finalidade como dificilmente se apurariam as faltas ao Serviço... Como os servidores podem faltar 3 dias ao mês por doença, desde que justifique essas faltas, poderíamos afirmar que um mau funcionário (o que não constitui peça rara de museu) poderia faltar 36 dias por ano, sem o perigo sequer de abandono de cargo, ou de ser demitido na forma do $\S 2$. do art. 207 do Estatuto dos Funcionários.

O afastamento em virtude de férias é considerado como de efetivo exercício, sendo que aquilo que o Estatuto chama de "faltas justificadas" nada tem a ver com o instituto das férias. 
A interrupção das férias só poderá ocorrer no interesse do Serviço: no caso de calamidade pública, convocação para júri, convocação para o serviço militar ou para o serviço eleitoral. Fora disso, não será o funcionário obrigado a interromper suas férias regulamentares, nem mesmo por motivo de promoção, transferência ou remoção. Se for o caso, a contagem do prazo para a posse ou para o exercício se iniciará dia seguinte ao do término das férias.

Notar que a obrigatoriedade das férias perdura, em princípio, ainda que o funcionário esteja em gozo de licença. Mas as situações têm que ser examinadas individualmente para evitar abusos.

Caracteristicas das férias: a obrigatoriedade de serem elas concedidas e, em princípio, de serem gozadas em cada ano de exercício; continuidade, posto que a lei determina sejam elas gozadas em 30 dias consecutivos, sem interrupção; sendo de efetivo exercício o período em que são gozadas, todas as vantagens de ordem pecuniária são asseguradas ao servidor; são inacumuláveis, "salvo imperiosa necessidade do serviço" e, ainda assim, pelo máximo de 2 anos ou 2 períodos.

A fixação da época das férias não fica, como dissemos, ao bel-prazer do funcionário e, sim, à discrição do chefe da repartição, considerando o interesse e a conveniência do serviço. Vale assinalar que constitui falta grave, a nosso ver, entre um chefe em férias e seu substituto se ausente, deixando acéfala a repartição. $\mathrm{O}$ que aduzimos não raro acontece em áreas muitas vezes vitais da Administração e até mesmo em organizações bancárias.

O funcionário adquire direito de gozar as férias somente depois do primeiro ano de exercício. Assim, se o funcionário foi nomeado em fevereiro de 1972 somente em fevereiro de 1973 adquirirá direito às férias, isto é, de gozá-las, porque, a rigor, direito às férias ele passou a ter desde seu ingresso no Serviço Público. $O$ direito subjetivo se integra decorrido o primeiro ano de exercício.

As férias são gozadas, regra geral, no decorrer do ano a que corresponderem. A impossibilidade de acumulação teria dois motivos - a desaconselhável ausência prolongada do funcionário, o que resultaria em detrimento do serviço e a frustração do período prefixado pela lei como essencial para a recuperação das energias. Período demasiado longo de afastamento é duplamente contraproducente, pois que desfalca por muito tempo a repartição de um seu servidor, como sofre este uma desa- 
tualização dos conhecimentos que deve ter para o bom desempenho de suas atribuições. Contreiras de Carvalho entende, com muita propriedade, que a acumulação de periodos de férias pode ser onerosa para a Administração, "quando o servidor se acha investido em função gratificada, pois obriga o pagamento da gratificação de função ao substituto". (Obra citada, p. 316.)

Somos dos que pensam que as férias poderiam ser parceladas, em período nunca inferior a 10 dias, mesmo porque nem sempre o funcionário tem condições para desfrutar, como convém, todo o período de férias que a lei lhe garante.

Por muito tempo esteve em vigor entendimento de que as férias não podiam estender-se além do ano civil, até que sobreveio o parecer do Dr. Clenício da Silva Duarte, um dos Consultores-Jurídicos do DASP, devidamente aprovado pelo Sr. Diretor-Geral (Processo n? 11.495/67 - Diário Oficial de 13 de fevereiro de 1968), que aduziu: "Não há qualquer norma que justifique a interpretação que proibia a transposição do ano civil no período de férias. Em casos especiais, como o de completar-se o primeiro ano de exercício em dias do mês de dezembro, impõe-se essa transposição, sob pena de descumprimento da norma vigente inserta no art. 84 do Estatuto dos Funcionários".

Cabe notar que, no âmbito administrativo, são inegociáveis as férias, e essa regra acreditamos se deva aplicar até ao pessoal regido pela legislação trabalhista, salvo no caso de dispensa ou rescisão do contrato de trabalho, desde que, é claro, o empregado já tenha direito adquirido a gozá-las.

$\mathrm{Na}$ empresa privada é possível, também, a percepção do salário adiantadamente, para que o empregado tenha condições financeiras para gozar suas férias. Acontece, porém, que, com isso, após as férias, passa situação financeiramente difícil. O mesmo aconteceria se o funcionário percebesse adiantadamente... O remédio, quanto a este, que já não goza do privilégio de ter gratificação natalina ou o 13:-salário, seria conferir-lhe um mês de vencimento para o efetivo gozo de suas férias anuais. Se não as gozasse, como no caso de chefias e assessoramentos superiores, faria," o funcionário, jus à vantagem financeira em cada período, sem a iniquidade da prescrição contra o servidor quando a acumulação das férias foi a favor da Administração.

Fica a idéia. . . 
Vale notar que o funcionário, durante o período de férias, não perde direito a qualquer vantagem que auferia enquanto em exercício, pois que aquele período é considerado como tal.

Os funcionários que operam com Raios $X$ e substâncias radioativas, próximos às fontes de irradiação, têm direito a regime especial de trabalho, como se sabe, de acordo com a Lei no 1.234, de 14 de novembro de 1950. Deverá trabalhar nunca mais de 24 horas semanais e ter férias de 20 dias consecutivos por semestre de atividade profissional, não acumuláveis, além de uma gratificação especial que deverá ser paga ainda que no gozo das férias.

As férias, aqui, são obrigatórias não só para que sejam concedidas mas para que sejam efetivamente gozadas. Não acumuláveis, aqui, não é para que o servidor perca se não gozar cada período, mas, sim, para que não some dois períodos porque os dois períodos de férias somados não afastam os malefícios que, acaso, a exposição por dois semestres às substâncias radioativas já produziram no organismo do servidor. Em cada semestre é impositivo um período de 20 dias consecutivos de afastamento, sem possibilidade nenhuma de parcelamento porque seria colocar em risco a saúde do servidor.

Também o magistério desfruta de férias especiais que devem coincidir com as férias escolares a serem gozadas entre os dois períodos letivos. Consoante o Estatuto do Magistério Superior, "as férias do pessoal docente de ensino superior terão a duração máxima de trinta dias, devendo ter lugar no período de férias escolares, fixado no calendário de forma a atender as necessidades didáticas e administrativas do estabelecimento". Essa regra se aplica ao magistério vinculado à esfera federal.

Em matéria de férias, há um pormenor muito importante para os servidores requisitados para órgãos da Justiça Eleitoral: se não gozarem eles as férias, de um período, em razão de suas funções, poderão gozá-las ano seguinte, acumuladas ou não, ou requerer sejam contadas pelo dobro, para efeito de aposentadoria. Acontece, porém, que o servidor deve estar alerta porque pode prescrever seu direito se não diligenciar, em tempo hábil, no sentido de comprovar que foi obrigado a acumular as férias por necessidade do serviço, a fim de gozálas cumulativamente em tempo oportuno ou para que fique isso consignado em sua ficha funcional, para efeito de aposenta-
doria. 
Matéria precipuamente de natureza regulamentar, ou meIhor, do âmbito da competência da Administração Pública, é o regime de trabalho do servidor público.

Já teve o DASP oportunidade de afirmar que o Governo tem a faculdade de fixar, como aprouver aos interesses do serviço público, o número de horas de trabalho de cada repartição.

E evidente que o legislador não está impedido de consubstanciar em lei a duração do trabalho do servidor, porém não deveria, em princípio, fazê-lo.

A jornada de trabalho tem estreita relação com as especificações de classe, vale dizer, com a natureza das atribuições específicas de cada categoria funcional.

Em pesquisa que fizemos, verificamos que o assunto merece ser revisto novamente por ocasião do novo plano de classificação de cargos, naturalmente com a assistência de um órgão técnico de competência especifica.

Juntamente com o levantamento das atribuições de cada categoria funcional deverá ser fixada uma carga horária tendo em vista uma política de higiene do trabalho.

Embora basicamente devam ter os servidores públicos um só horário, há que ser considerado cada caso de per si para evitar abusos e injustiças.

Dentro de um critério de agrupamento que estabelecemos para inserir várias hipóteses dentro do ordenamento existente, verificamos que efetivamente o assunto merece reexame geral pelo menos para balizar a jornada dentro de critérios mais racionais, flexiveis e justos.

Vejamos os quatro grupos em que dispomos as várias hipóteses examinadas.

No primeiro Grupo, integrado por servidores sujeitos a 200 horas mensais de trabalho, de conformidade com o disposto no art. 6 ? do Decreto no 26.299 , de 31 de janeiro de 1949, foram colocados pelo DASP os servidores que executam encargos de natureza industrial agrícola, marítima, braçal ou de tipo similar, inclusive os de vigilância: Auxiliar de Inspeção Sanitária e Rural, Assistente de Organização Rural, Auxiliar Rural, Auxiliar de Laboratório, Auxiliar de Portaria, Auxiliar de Artífice, Artífice Maquinista, Bombeiro Hidráulico, Balconista, Classificador de Produtos Animais e Vegetais, Condutor Motorista, 
Carpinteiro, Cozinheiro, Eletricista Instalador, Eletricista Enrolador, Feitor, Ferreiro, Funileiro, Guarda, Inspetor de Corte e Seringa, Inspetor de Campo, Inspetor de Guardas, Laboratorista, Mestre Rural, Mestre, Motorista, Marinheiro, Mecânico de Máquinas, Mecânico de Motores a Combustão, Operário Rural, Porteiro, Prático de Farmácia, Pintor, Pedreiro, Serviçal, Serraiheiro, Soldador, Técnico Rural, Telegrafista, Tratorista.

Neste Grupo, a nosso ver, há alguns casos que merecem ser revistos, até com certa urgência em benefício da própria disciplina.

No segundo Grupo, integrado por servidores burocratas sujeitos a 32 horas e 30 minutos semanais de trabalho, nos termos do Decreto n? 51.320 , de 2 de setembro de 1961, foram colocadas as seguintes categorias: Arquivista, Assistente de Administração, Auxiliar de Estatística, Almoxarife, Atendente, Armazenista, Correntista, Datilógrafo, Escriturário, EscreventeDatilógrafo, Enfermeiro-Auxiliar, Oficial de Administração, Técnico de Contabilidade e Tesoureiro.

No terceiro Grupo, integrado por servidores ocupantes de cargos de nível universitário sujeitos à prestação mínima de 30 horas semanais de trabalho, foram colocadas as seguintes categorias profissionais: Cirurgião-Dentista, Economista, Engenheiro-Agrônomo, Médico Veterinário, Químico, às quais poderiam juntar-se o Assistente Jurídico, o Médico, o Engenheiro Civil, a Enfermeira etc.

No quarto Grupo, ficou o pessoal docente dos estabelecimentos federais de ensino, não regido pelo Estatuto do Magistério Superior, sujeito, ainda, a 18 horas semanais de trabalho, empregadas preferencialmente em aulas, de acordo com o art. 5\% do Decreto no 26.299, de 31 de janeiro de 1949: o Professor Ruralista e o Professor de Ensino Pré-Primário e Primário.

O expediente das repartições públicas federais e o horário de trabalho do funcionalismo estão, de modo geral, regulados pelo Decreto no 51.320 , de 2 de setembro de 1961 , decre to esse que, igualmente, suprimiu o expediente aos sábados. Determinou esse regulamento que as repartições públicas do Poder Executivo, as autarquias e demais entidades autônomas funcionarão, normalmente, de segunda a sexta-feira, das 11 às 17 horas e 30 minutos.

Estabeleceu, ainda, que as repartições fiscais ou arrecadadoras, industriais, de assistência social, médicas, hospitalares, 
dentárias, os estabelecimentos escolares e as autarquias de natureza bancária poderão ter expediente especial, observado o mínimo semanal de 32 horas e 30 minutos. A essas entidades, - Decreto n? 59.275, de 23 de setembro de 1966, acrescentou: "os órgãos em que se executem serviços de processamento de dados e apuração mecânica".

Consoante aquele Decreto n? 51.320 , de 1961, os servidores civis do Poder Executivo, das autarquias e demais entidades autônomas ficam sujeitos ao horário de 32 horas e 30 minutos semanais de trabalho. Foram excluidos desse regime de trabalho os servidores que, nos termos do Decreto n? 26.299, de 31 de janeiro de 1949 , devem prestar 200 horas mensais de trabalho, bem como os servidores sujeitos a regime especial fixado em lei.

De acordo, ainda, com o que dispõe o Decreto n? 51.320 , de 1961; os ocupantes de cargos de Médico no Serviço Público Civil do Poder Executivo, das autarquias e demais entidades autônomas ficaram obrigados ao regime de 30 horas semanais de trabalho, observadas as escalas de serviço organizadas pelos chefes de repartição, incluindo as atividades dos sábados, domingos e feriados. De conformidade com o disposto no art. 3 ? do Decreto n? 57.825 , de 16 de fevereiro de 1966 , o ocupante de cargo ou emprego de nível universitário está sujeito à prestação mínima de 30 horas semanais de trabalho. Assim é que Médicos, Dentistas e Auxiliares, no Serviço Público Federal, têm a jornada de trabalho fixada em 30 horas semanais, e não nos termos da Lei n? 3.999 , de 13 de dezembro de 1961, que fixou essa jornada em 2 horas no mínimo e 4 no máximo para aquelas categorias profissionais no âmbito da empresa privada, conforme tem entendido a Administração.

Como o disciplinamento positivo existente deixa pouca margem para situar as várias categorias funcionais, a Administração tem aplicado o princípio da analogia para resolver certas dúvidas, embora o assunto mereça, como dissemos, uma revisão calcada em pronunciamento de um órgão especializado.

Assim é que às Telefonistas, por exemplo, foi aplicado o regime de 32 horas e 30 minutos semanais de trabalho porque suas funções teriam mais similitude com as atribuições burocráticas..., o mesmo acontecendo com os Atendentes. O Ascensorista está sujeito a 200 horas mensais de trabalho, enquanto os Cabineiros de elevador, regidos pela legislação trabalhista, têm horário especial fixado pela Lei $n$ ? 3.270 , de 30 de setembro de 1957, isto é, 6 horas diárias de trabalho, sem possibilidade de qualquer acordo que vise a seu aumento. 
Já os Redatores e Revisores do Serviço Público desfrutam de horário especial, de conformidade com o Decreto no 52.959 , de 26 de novembro de 1953, que é de 5 horas diárias de trabalho, embora a Consultoria-Geral da República, no Parecer $\mathrm{n}$ \% $172-\mathrm{H}$, de 27 de abril de 1965, estranhasse o privilégio. A esse mesmo regime está sujeito o pessoal lotado nas Oficinas de Estereotipia, bem como nos serviços de fundição da Divisão de Produção do Departamento de Imprensa Nacional, o que nos parece justo, dada a natureza do trabalho.

Os servidores civis do Centro Técnico de Aeronáutica, do Ministério da Aeronáutica, qualquer que seja sua classificação, categoria ou regime, estão obrigados à prestação de 44 horas semanais de trabalho, ressalvados aqueles servidores que executem encargos de natureza industrial, braçal, ou de tipo similar, inclusive os de vigilância, e os confiados ao pessoal de obras, aos carteiros, serventes, contínuos e porteiros, sujeitos a 200 horas mensais. Igual é o regime de trabalho dos servidores da Administração do Porto do Rio de Janeiro, com idêntica ressalva. Desse regime foram excluídos os Guardas da Polícia Portuária. Os servidores da Administração do Porto do Rio de Janeiro que exerçam atividades estritamente policiais, estão sujeitos à prestação de 200 horas mensais de trabalho. Esses períodos de trabalho são fixados pelo Superintendente, mediante proposta do Chefe da Divisão de Polícia Portuária, segundo a conveniência do serviço, observado o limite máximo de 8 horas para a jornada ordinária e as normas de higiene de trabalho, obedecida uma folga semanal de 24 horas. Se, por qualquer circunstância, for necessária a continuidade do serviço, a jornada de trabalho poderá ser alterada, gratificando-se o serviço extraordinário sempre que ultrapassar o limite de 8 horas. Os serviços aos sábados, desse pessoal, devem ser remunerados de modo especial, pois que são considerados serviços extraordinários.

O trabalho executado entre as 22 horas de um dia e as 5 horas do dia seguinte é considerado noturno também no âmbito da Administração Pública. Cabe notar que, para ocupantes de determinados cargos, como os de Enfermeiro, os de Vigia, os de Guarda, o horário entre 22 horas de um dia e as 5 do dia seguinte não constitui serviço extraordinário, isto porque serviço extraordinário é aquele que decorre de antecipação ou de prorrogação de horário normal de trabalho, que enseja gratificação especial paga por hora de trabalho a maior.

Quando o Estatuto dos Funcionários diz que, em se tratando de serviço extraordinário noturno, o vâlor da hora será 
acrescido de $25 \%$, refere-se àquele serviço prestado além do horário normal de trabalho a ultrapassar as 22 horas de um dia ou a se antecipar às 5 horas da manhã do dia seguinte.

Sempre achamos que o trabalhador que execute suas tarefas à noite deveria ter tratamento especial, quanto mais não fosse uma jornada mais reduzida. No entanto, admite-se que o trabalho de Vigia seja "mais suave que o dos trabalhadores em geral", podendo ser-lhe atribuído um horário de dez horas diárias nos termos da legislação trabalhista (Cf. Altamirando J. Casais, Duração do Trabalho, Ed: Lerfixa, 1971 (?), p. 25).

Os Agentes Fiscais de Rendas Internas, do Imposto de Renda, do Imposto Aduaneiro etc. estão obrigados a 40 horas semanais de trabalho, podendo a jornada, diurna ou noturna, estender-se aos sábados, domingos e feriados, conforme o interesse do Tesouro Nacional, considerando o volume e a urgência das atividades específicas dos órgãos da Administração Fiscal. Aqueles antigos Agentes hoje são denominados Agentes Fiscais dos Tributos Federais, mas o regime de trabalho ficou inalterado.

Os ocupantes de cargos em comissão e de funções gratificadas estão sujeitos à prestação de 35 horas semanais de trabalho, jornada que poderá ser elevada até 40 horas.

O servidor contratado pela legislação trabalhista está sujeito a oito horas diárias de trabalho. Já entendeu a Administração que se esses servidores exercem atividades iguais às dos funcionários sujeitos à prestação de 6 horas e 30 minutos de trabalho diário, na mesma repartição, e percebem salários não superiores aos vencimentos dos funcionários, pode ser dispensado o cumprimento de 8 horas de trabalho. Esse entendimento deverá ser aplicado com as devidas cautelas.

Tem o funcionário pequeno intervalo de 30 minutos para merenda, espaço de tempo esse computado no horário de trabalho sem que possa ser descontado para efeito algum. Salvo os que trabalham em regime de dois turnos, de 4 horas cada.

O Médico, como se sabe, atualmente pode acumular dois cargos de igual natureza, devendo perfazer, no exercício de cada um, 30 horas semanais de trabalho, de conformidade com as normas estabelecidas internamente pela repartição ou estabelecimento hospitalar onde servir. Assim são os cargos de Médico-Analista, Médico-Auxiliar, Médico-do-Trabalho, MédicoLegista, Médico-Nutrólogo, Médico-Psiquiatra, Médico-Puericultor, Médico-Sanitarista, Médico-Urologista etc. Já o mesmo não acontece com o Médico-Radiologista que desfruta de regime 
especial de trabalho, de conformidade com a Lei no 1.234, de 14 de novembro de 1950: está ele sujeito ao regime máximo de 24 horas semanais de trabalho; tem direito a férias de 20 dias consecutivos, por semestre de atividade profissional, férias essas não acumuláveis, além de uma gratificação adicional de $40 \%$ do vencimento. O Médico-Radiologista, por isso mesmo, como medida de higiene do trabalho, por lidar com Raios $X$ e substâncias radioativas, não pode exercer outro cargo de igual natureza, nem mesmo ser professor de disciplina que o obrigue a manipular aparelhos de Raios $X$ ou substâncias radioativas. Esclareça-se que esse entendimento é de aplicar, igualmente, no caso de Médico que, "embora não especialista, realiza atividades junto às fontes de irradiação, como complemento de suas atribuições", isto é, na hipótese referida no art. 10 do Decreto $n$ ? 43.185, de 6 de fevereiro de 1958. O Operador de Raios X, se sujeito ao mesmo regime de trabalho, está impossibilitado, igualmente, de exercer a mesma atividade ainda que em entidade particular.

A licença em caráter especial está prevista no artigo 116 do Estatuto dos Funcionários Públicos Civis da União (Lei n? 1.711 , de 28 de outubro de 1952).

E a antiga e conhecida licença-premio criada pela Lei no 42 , de 15 de abril de 1935 , revogada pelo artigo 278 do antigo Estatuto, de 1939, e restabelecida pela Lei no 283 , de 24 de maio de 1948, regulamentada pelo Decreto no 25.267 , de 28 de julho de 1948.

Essa licença esteve, assim, em eclipse total por mais de oito anos, havendo sido restabelecida, como uma conquista do servidor público, pelo regime constitucional de 1946.

$\mathrm{O}$ atual Estatuto dos Funcionários (Lei no 1.711, de 28 de outubro de 1952) acolheu a legislação que restabeleceu a licença, consubstanciando a matéria nos artigos 116 e 117, que foram regulamentados pelo Decreto $n \div 38.204$, de 3 de novembro de 1955 , cujo artigo 8 ? teve nova redação dada pelo Decreto no 50.408 , de 3 de abril de 1961.

Essa licença é de seis meses com todos os direitos $\theta$ vantagens do cargo efetivo, concedida ao funcionário, que a requerer, após cada decênio de efetivo exercicio.

De modo que, fator preponderante para concessão da licença especial é perfazer o funcionário certo tempo de serviço. 
Donde se infere, de logo, que o nome licença-especial é menos apropriado que licença-premio, dada a natureza de sua destinação.

O objetivo é premiar o servidor que trabalhou durante dez anos, sem faltas, sem haver sofrido pena de suspensão, sem haver gozado licença além de certo limite que a lei especifica. Seriam umas férias especiais a título de prêmio que, se não gozadas, abreviariam pelo duplo do período o lapso de tempo computável para a aposentadoria.

Assim, um funcionário que se aposenta com 35 anos de serviço e já tem três períodos em que não gozou licença especial, com um pouco mais de 31 anos já poderá requerer sua aposentadoria.

O preceito estatutário especifica os motivos que ensejam a interrupção da contagem do período aquisitivo:

a) se o funcionário, nesse lapso de tempo, sofrer pena de suspensão;

b) faltar ao serviço injustificadamente;

c) houver gozado licença para tratamento de saúde por mais de 6 meses ou 180 dias, consecutivos ou não;

d) houver se licenciado por motivo de doença em pessoa da família, por mais de 4 meses ou 120 dias; ticulares;

e) houver se licenciado para o trato de interesses par-

f) houver se licenciado por motivo de afastamento do cônjuge, quando funcionário ou militar, por mais de 3 meses ou 90 dias.

Não ocorrendo nenhuma dessas circunstâncias, não será considerado interrompido o período aquisitivo do benefício, que Outra coisa não é a licença especial. cionada.

Notar que, cessada a interrupção do período, começará a Correr nova contagem do decênio.

O cômputo do decênio de efetivo exercício está disciplinado pelo Decreto n? 38,204, de 3 de novembro de 1955.

De conformidade com esse regulamento, "entende-se como tempo de efetivo exercício o que tenha sido prestado à União, em cargo ou função civil ou militar, ininterrupta ou consecutivamente, em órgãos de administração direta, apurado à vista dos 
registros de freqüência, folhas de pagamento ou dos elementos regularmente averbados no assentamento individual do funcionário".

A contagem será feita em dias e o total apurado convertido em anos, sem possibilidade de arredondamento.

De efetivo exercício é considerado o afastamento em virtude de férias; casamento; luto; exercício de outro cargo federal de provimento em comissão; em virtude de convocação para serviço militar; júri e outros serviços obrigatórios por lei; desempenho de função ou cargo de governo ou administração, em qualquer parte do território nacional, desde que por nomeação do Presidente da República; licença especial; licença à funcionária gestante, ao funcionário acidentado em serviço ou atacado de doença profissional; em virtude de licença, até 0 limite de dois anos, ao funcionário acometido de tuberculose ativa, alienação mental, neoplasia maligna, cegueira, lepra, paralisia irreversivel e incapacitante, cardiopatia grave, doença de Parkinson etc.; em virtude de missão ou estudo no estrangeiro, quando o afastamento houver sido autorizado pelo Presidente da República; e, finalmente, exercício, em comissão, de cargos de chefia nos serviços dos Estados, do Governo do Distrito Federal, dos Municipios ou Territórios.

São, ainda, considerados de efetivo exercício os dias que, na vigência da legislação anterior ao antigo Estatuto de 1939 , foram considerados como faltas justificadas, bem como as faltas relevadas durante o mês, por motivo de doença comprovada em inspeção médica, além da falta do funcionário estudante nos dias de prova ou exame.

Cumpre observar que os dias intermediários no exercício de um cargo, quando forem sábado, domingo, feriado ou de ponto facultativo, não interromperão o curso do decênio.

Se o funcionário efetivo ocupar cargo em comissão ou estiver no exercício de função gratificada deverá afastar-se durante o lapso de tempo em que estiver no gozo da licença, percebendo - reparem bem - somente o vencimento ou remuneração do cargo de que seja ocupante efetivo.

Neste caso, a substituição será remunerada durante todo o período do afastamento do titular.

E certo que é vedado converter a licença em dinheiro, mas entendemos que essa norma poderia ser reexaminada pois que, a nosso ver, é de maior interesse da Administração que sel servidor não se afaste por tanto tempo do serviço, numa desa- 
tualização perniciosa ao profissional, que mesmo retribuir em dinheiro aquilo que é um premio.

Ao funcionário, sempre uma recompensa em dinheiro the serve e agrada mais que férias ou licenças ainda que especiais.

Como o funcionário pode capitalizar o tempo para tê-lo contado em dobro para efeito de aposentadoria, tem acontecido que muitos morrem antes de se aposentar, exonerando-se, assim, a Administração de conferir o favor ainda que aos dependentes do falecido.

Se a licença pudesse ser convertida em dinheiro, muitas situações difíceis se resolveriam antes e depois da morte do Servidor.

Outro aspecto importante: a possibilidade de se computar em dobro o tempo para efeito de gratificação adicional por tempo de serviço. Providência justa que merece estudo por parte do legislador, sendo o assunto, constitucionalmente, de iniciativa do Senhor Presidente da República.

Vamos fazer alguma coisa de útil para o funcionário a título de estímulo ou motivação, quem sabe se até como matéria de sobrevivência!

Em caso de acumulação de cargos, a licença especial será concedida em relação a cada um dos cargos, simultânea ou separadamente. Será independente o cômputo do decênio em relação a cada um, cumprindo advertir que o tempo de serviço prestado anteriormente à acumulação somente poderá ser computado para contagem de decênio concernente ao cargo em que o interessado contar maior tempo de serviço.

Se um Escriturário estiver no gozo de licença especial, poderá ser nomeado para um outro cargo de igual natureza ou de prufessor?

Certamente que não. Só poderia ser nomeado se o cargo em razão do qual entrou em licença é acumulável com ele. Assim, um licenciado do cargo de Técnico de Administração poderá ser nomeado, digamos, para um cargo de Professor de Administração.

Cabe observar que, embora a licença especial seja de 6 meses, poderá ser ela gozada parceladamente, e isso seria de conveniência até para a Administração. É claro que o funcionário deverá comunicar à autoridade competente como deseja gozar a licença, especificando a forma, nada impedindo que, desejando, de início, desfrutar de uma só vez o semestre, re- 
solva interromper a licença para voltar a gozar o período restante em outra ocasião. Será sempre necessário que comunique o fato, por escrito, à autoridade competente.

A escala de licenças será organizada por determinação do chefe de repartição ou serviço, devendo obedecer à ordem cronológica de entrada dos requerimentos dos funcionários interessados, escala essa que poderá ser revista, conforme as circunstâncias.

Caso um funcionário seja autorizado a reassumir o exercício porque desistiu, 2 meses depois, de continuar no gozo da licença especial, entendemos que o período restante - 4 meses - pode ser computado em dobro, no seu devido tempo, para efeito de aposentadoria. Ponto-de-vista nosso.

Quando o funcionário possuir dois ou mais decênios ininterruptos de serviço, e quiser gozar, de uma só vez, a licença a que faz jus, os períodos semestrais consecutivos correspondentes a cada uma deverão ser fixadas, distintamente, com a data do início e do término de cada um deles, caso não haja, naturalmente, inconveniente para o serviço, ficando o assunto um tanto à discrição da chefia.

Dissemos, de início, que a licença especial será concedida "com todos os direitos e vantagens" do cargo efetivo. Essa expressão - direitos e vantagens - já entendeu o DASP, só alcança os mesmos direitos e vantagens decorrentes, necessariamente, do exercício do cargo, a eles não se somando direitos e vantagens oriundos de condições outras, não ligadas a essa titularidade.

Notar, por derradeiro, que funcionário afastado para exercer mandato eletivo só tem assegurada a contagem do tempo para promoção por antiguidade e para aposentadoria, não, por conseguinte, para fins de licença especial ou para que possa ser contado em dobro esse período de licença não gozada para fins de aposentadoria. 